\title{
Correction to: Fire Management in The Boreal Forest of Swedish Sápmi: Prescribed Burning and Consideration of Sami Reindeer Herding During 1920-1970
}

Sarah Cogos $\mathbb{D}^{1,2} \cdot$ Lars Östlund $^{2} \cdot$ Samuel Roturier $\mathbb{D}^{1}$

Published online: 19 August 2021

(c) Springer Science+Business Media, LLC, part of Springer Nature 2021

Correction to: Environmental Management

https://doi.org/10.1007/s00267-021-01503-9

The original version of this article unfortunately contained a mistake. The authors given and family names were incorrectly structured as "Cogos Sarah, Ostlund Lars and Roturier Samuel". The author names have now been corrected.

The original article has been corrected.

Sarah Cogos

sarah.cogos@protonmail.com

1 Université Paris-Saclay, CNRS, AgroParisTech, Ecologie Systématique Evolution, F-91405 Orsay, France

2 Department of Forest Ecology and Management, Swedish University of Agricultural Sciences, 90183 Umeå, Sweden 